\section{Influence of Sealer and Light-Curing Units on Push-Out Bond Strength of Composite Resin to Weakened Roots}

\author{
Adriana Corrêa de Lima, Fuad Jacob Rached-Junior, Natália Spadini de \\ Faria, Danielle Cristine Messias, Carolina de Andrade Lima Chaves, Jessica \\ Vavassori de Freitas, Flares Baratto-Filho, Yara Teresinha Corrêa \\ Silva-Sousa
}

Department of Dentistry, Positivo

University, Curitiba, PR, Brazil

Correspondence: Profa. Dra. Yara

T Corrêa Silva Sousa, Rua Célia

de Oliveira Meirelles 350, Jardim

Canadá, 14024-070 Ribeirão Preto,

SP, Brasil. Tel: +55-16-3603-

6717. email: ysousa@unaerp.br
The aim of this study was to assess the influence of sealer and light-curing unit on regional bond strength of resin composite to the weakened roots. Ninety roots of incisors were experimentally weakened, subjected to biomechanical preparation and filled with either Endofill, AH Plus or MTA Fillapex The roots were desobturated e reinforced with resin composite and fiber post light-activated with one of the light sources: halogen at $600 \mathrm{~mW} / \mathrm{cm}^{2}$ (QTH-600), LED at $800 \mathrm{~mW} / \mathrm{cm}^{2}$ (LED-800) and LED at $1500 \mathrm{~mW} / \mathrm{cm}^{2}$ (LED-1500). The roots were sectioned in slices from cervical, middle and apical rootreinforcement regions and analyzed by push out test, scanning electron microscopy (SEM) and confocal laser scanning microscopy (CLSM). Bond strength data were analyzed using three-way ANOVA and Tukey's test $(\alpha=0.05)$. Specimens filled with AH Plus had higher bond strength, followed by MTA Fillapex and Endofill $(p<0.05)$. For light-curing unit, LED-1500 presented superior bond strength than LED-800, which was higher than 0TH-600 $(p<0.05)$. The cervical region had the greatest mean values $(p<0.05)$ while apical part showed the lowest bond strength $(p<0.05)$. CLMS revealed remaining filling material in the dentinal tubules for all groups. The eugenol-containing sealer (Endofill) compromised the push-out bond strength of composite resin to the root dentin. Bond strength was favored in the cervical region, and when LED-1500 was used.
Key Words: Bond strength, composite resin, dentin, light-curing, sealer.

\section{Introduction}

In cases of excessive root canal flaring, resin materials that have similar elastic modulus with dentin can be used to reinforce weakened roots $(1,2)$. The stability of this procedure depends on the bond strength of the composite resin along the root canal (1).

Residual filling materials could have an adverse effect on the resin bonding to root canal dentin. Its effect as mechanical barrier obstructs proper adhesive infiltration and impairs the chemical interaction of the resin material with dentin (3). Furthermore, the composition of endodontic sealers might interfere with bonding ability of resin material.

Among the root canal sealers available to the endodontic procedure there are the sealers based on epoxy resin, which present satisfactory physical properties and adequate biological performance, the calcium-silicatebased materials that may stimulate biological response in the apical region and the eugenol-containing sealers that are still the widely employed due to their long history of clinical success (3). Studies have shown decreased bond strength when eugenol-based sealer was used before root reinforcement $(3,4)$ by disturbing the polymerization reaction of resin cement $(3,4)$. Despite concerns about the influence of the remaining sealer on the adhesion of the reinforcement material to the root canal walls, the effect of the components of endodontic fillings on polymerization of resin materials remains unclear.

The monomer conversion in resin materials achieved by light-activation is another important factor for bonding to the root dentin $(1,5)$. The curing of the composite resin may be influenced by the power density delivered (6) and the wavelength emitted (7) by the light-curing unit. In the apical areas, the limited reach of light results in deficient polymerization of the resin material and compromises the adhesion to the dentin (8).

Despite, the light emitting-diodes (LEDs) curing units be currently used for photo-activation, quartz-tungsten halogen lamp (OTH) curing units are still used (9). OTH emits light from a halogen bulb, which is filtered by a dielectric pass-band filter, and selectively transmits a desired wavelength range between 350 and $700 \mathrm{~nm}$, able to activate different photo-initiators $(6,10)$. Due to drawbacks of QTH such as generation of high temperatures and limited lifespan, LED technology has been indicated as an alternative to light-activate resin materials $(6,10)$. LED is formed by junctions of doped semiconductors to generate light with a narrow specter $(440-490 \mathrm{~nm})$ (11). LED units have increased lifetime, undergo little degradation over time, do not require filters to produce blue light and 
are able to reach higher power density than other light sources (12).

Therefore, the present study assessed the effect of the remaining sealer of different bases (epoxy resin, calcium silicate and zinc oxide eugenol) on regional bond strength to the dentin of roots reinforced with composite resin and fiber posts light-activated with OTH at $600 \mathrm{~mW} / \mathrm{cm} 2$, LED at $800 \mathrm{~mW} / \mathrm{cm} 2$ and LED at $1500 \mathrm{~mW} / \mathrm{cm} 2$. The analysis was performed by push out test, complemented by scanning electron microscopy (SEM) and confocal laser scanning microscopy (CLSM). The hypothesis behind this study was that the remaining sealer of different bases and the light curing units can affect the regional bond strength of composite resin to weakened roots.

\section{Material and Methods}

This study was submitted and approved by the Ethical Committee of University of Ribeirão Preto, SP, Brazil.

Maxillary human canines stored in $0.1 \%$ thymol solution steam at $9^{\circ} \mathrm{C}$ were washed in running water for $24 \mathrm{~h}$ to eliminate thymol residues. Teeth were macroscopically examined and radiographed in mesiodistal direction. Ninety teeth with root completely formed and presenting single canal without calcifications or accentuated curvature were selected.

The crowns were removed at the cementoenamel junction (root length $17 \mathrm{~mm}$ ) using a diamond disk (Brasseler Dental Products, Savannah, GA, USA) with water spray cooling (Dabi Atlante Ltda, Ribeirão Preto, SP, Brazil).

The working length was determined visually by subtracting $1 \mathrm{~mm}$ from the length of a $15 \mathrm{~K}$-file (Dentsply Maillefer, Ballaigues, Switzerland) at the apical foramen. The canals were instrumented with Gates Glidden drills from \#2 to \#4 at the coronal third and with ProTaper rotary system (Dentsply Maillefer, Tulsa, OK, USA) according to a crown-down technique to a size 50.02 taper to the working length. Root canals were irrigated with $2 \mathrm{~mL}$ of $1 \% \mathrm{NaOCl}$ between each file size instrumentation and, after preparation, the canals were irrigated with $5 \mathrm{~mL}$ of 17\% EDTA ( $\mathrm{pH}=7.7$ ) for $5 \mathrm{~min}$ followed by a final 1-min 2- $\mathrm{mL}$ rinse with deionized water.

Roots were experimentally weakened (13) by reducing the thickness of the dentin from canal walls using highspeed diamond burs \#4137 (Vortex Ind. e Com., São Paulo, SP, Brazil) and KG 717 (KG Sorensen, São Paulo, SP, Brazil) up to $12 \mathrm{~mm}$ from the root canal length.

Fiber posts (White Post DC \#2; FGM, Joinville, SC, Brazil) with $1.8 \mathrm{~mm}$ diameter at the cororal portion and $1.5 \mathrm{~mm}$ at the apical portion were individually tested in the root canal to ensure the presence of a $1.0 \mathrm{~mm}$ space between the post and intraradicular dentin surface. Roots were irrigated with $10 \mathrm{~mL}$ of $1 \% \mathrm{NaOCl}$ followed by a final rinse with $2 \mathrm{~mL}$ deionized water.

Roots were filled with the sealer assigned for each group: Endofill (Dentsply, Petrópolis, RJ, Brazil), AH Plus (Dentsply De Trey, Konstanz, Germany) and MTA Fillapex (Angelus, Londrina, PR, Brazil). The sealers were mixed with $0.1 \%$ fluorescein during manipulation and were inserted with gutta percha cones using the lateral compaction technique (Dentsply-Maillefer, Petrópolis, RJ, Brazil).

After a period corresponding to three times the setting time of the sealers, the filling material was removed up to a depth of $12 \mathrm{~mm}$ using the preparation drill of the fiber post system (White Post DC; FGM, Joinville, SC, Brazil) and heated pluggers (Maillefer, Tulsa, USA).

Root canals were irrigated with $10 \mathrm{~mL}$ deionized water and dried with absorbent paper points. Root dentin was etched with 35\% phosphoric acid (3M ESPE, St. Paul, MN, USA) under agitation with a file for $15 \mathrm{~s}$, rinsed with 20 $\mathrm{mL}$ of deionized water for $15 \mathrm{~s}$, and dried with absorbent paper points. A three-step etch-and-rinse adhesive system (Adper Scotchbond Multipurpose; 3M ESPE) was applied to the slightly moist dentin with disposable microbrush tips, following the manufacturer's instructions. A mass of $0.1 \%$ rhodamine fluorescent dye was added to the bonding agent before applying it to the dentin surfaces. The lightactivation was performed with one of the light-curing units allocated for each sub-group ( $n=10)$ : a- OTH lamp at 600 $\mathrm{mW} / \mathrm{cm}^{2}$ (OTH-600, Ultralux; Dabi Atlante, Ribeirão Preto, SP, Brazil); b- LED at $800 \mathrm{~mW} / \mathrm{cm}^{2}$ (LED-800, Spaceled; Ecel, Ribeirão Preto, SP, Brazil); and c- LED at $1500 \mathrm{~mW} / \mathrm{cm}^{2}$ (LED-1500, Radii Plus; SDI Ltd., Bayswater, Vic, Australia). The energy density used for each group was OTH-600: 24J/

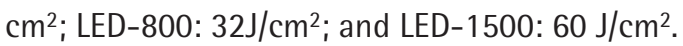

The dowel spaces from weakened roots were filled with composite resin (Z250, 3M ESPE, St. Paul, MN, USA). Posts were covered with petroleum jelly and centrally inserted into the resin mass along the entire post space extension. The excess of material was removed and the composite resin was light-activated for $40 \mathrm{~s}$ with the allocated light-curing unit by placing the light tip on the remaining coronary post. Before each reinforcement procedure, the light output of each curing unit was checked with radiometer (Ecel, Ribeirão Preto, SP, Brazil) to ensure accurate light intensity. Fiber-reinforced posts were removed from the root canal, cleaned and sectioned horizontally with a water-cooled diamond disc (KG Sorensen, São Paulo, SP, Brazil) $4 \mathrm{~mm}$ above the coronal border of the root.

A thin layer of silane coupling agent (3M ESPE, St. Paul, MN, USA) was applied on the post surfaces, gently air-dried and light-cured for $10 \mathrm{~s}$. Fiber posts were luted with resin cement (RelyX U100, 3M ESPE), according to the manufacturer's instructions, and light-activated with the designated light-curing unit at $10 \mathrm{~mm}$-distance between 
the light tip and coronal remaining portion of the post. Specimens were stored in a dark container at $37^{\circ} \mathrm{C}$ for $24 \mathrm{~h}$.

Specimens were sectioned in slices of $1 \mathrm{~mm}$ thickness with a cutting machine (Buehler, Lake Forest, IL, USA) under water cooling. The first slice of each root-reinforcement region was polished and evaluated using a confocal inverted microscope (Leica TCS-SPE Leica, Mannheim, Germany) and a method of epifluorescence with wavelengths of absorption and emission to fluorescein of 536/617 nm. The samples were analyzed $10 \mu \mathrm{m}$ below the surface sample at $5 \times$ magnification.

After the qualitative analysis in confocal microscope, the same first slice was submitted to the push-out test in a universal testing machine (Instron Corporation, Canton, MA, USA) at a crosshead speed of $0.5 \mathrm{~mm} / \mathrm{min}$. A stainless steel support was used to hold the specimens in a standardized position. The force needed to dislodge the material ( $F$; in $\mathrm{kN}$ ) was transformed into tension ( $\sigma$; in $\mathrm{MPa}$ ) by dividing the force by the adhesive area of the resin (in $\mathrm{mm}^{2}$ ).

Failure types at the resin/dentin interface were analyzed under a stereoscopic microscope at $\times 40$ magnification (Leica Microsystems, Wetzlar, Germany), and displayed in percent. Failure was considered adhesive if it occurred at the dentin/resin interface, cohesive if it occurred in the material or the substrate, and mixed if it involved both the interface and the material.

The second slice obtained from each root-reinforcement region was prepared for SEM analysis of the resin material/ root dentin interface. Surfaces were prepared (14) and analyzed using a scanning electron microscope (JSM 5410; JEOL, Tokyo, Japan) operating at 15kV. SEM micrographs were obtained at $\times 15$ magnification for localization of representative areas and then at different magnification to evaluate the presence of failures at the interface with dentin.

After checking normality (Kolmogorov-Smirnov's test), data from push-out test were analyzed using threeway analysis of variance (sealer vs light-curing unit vs root-reinforcement region). Multiple comparisons were performed using Tukey's test at a 0.05 significance level (Statistical Package for the Social Sciences; SPSS Inc., Chicago, IL, USA).

\section{Results}

\section{Push-out Bond Strength to Root Canal Dentin}

Table 1 shows the bond strength of the resin material to root dentin in the different experimental conditions.

Three-way ANOVA detected significant differences for sealer $(p<0.05)$, light-curing unit $(p<0.05)$ and rootreinforcement region $(p<0.05)$. There was no significant interaction between the factors.

AH Plus had the highest bond strength values, followed by MTA Fillapex and Endofill, which were statistically different among them ( $p>0.05)$.

QTH-600 and LED-1500 showed the lowest and the highest means, respectively, with LED-800 showing an intermediate performance $(p<0.05)$.

Regional push-out bond strength was observed in decreasing order as follows: cervical>middle>apical $(p<0.05)$.

The most predominant failure pattern was adhesive (between dentin and composite resin), regardless of the sealer, light-curing unit and root-reinforcement region. In the cervical region of specimens filled with AH Plus and light-cured with LED-800 or LED-1500 there was a predominance of cohesive failures.

\section{SEM Analysis}

Photomicrographs showed that hybrid-layer formation could not be observed in all specimens. Gaps occurred between dentin and resin material in the specimens filled with Endofill (Fig. 1A) and MTA Fillapex (Fig. 1B). For AH Plus, gaps and an irregular and porous surface were observed between dentin and resin, and was associated with the presence of sealer remaining (Fig. 1C).

\section{Confocal Laser Scanning Microscopy}

In all groups (Figs. $2 A, B, C$ ), remaining filling material was observed into dentinal tubules along root canal walls and mixed with resin adhesive, which resulted in yellow

Table 1. Push-out bond strength (MPa) according to the root canal sealer, light-curing unit and root-reinforcement region.

\begin{tabular}{ll}
\hline Variable & Mean \pm SD \\
\hline Root canal sealer & $1.77 \pm 0.87 \mathrm{c}$ \\
Endofill & $4.22 \pm 1.99 \mathrm{a}$ \\
AH Plus & $3.63 \pm 1.71 \mathrm{~b}$ \\
MTA Fillapex & Mean \pm SD \\
Light-curing unit & $2.76 \pm 1.78 \mathrm{c}$ \\
QTH-600 & $3.06 \pm 1.77 \mathrm{~b}$ \\
LED-800 & $3.79 \pm 2.03 \mathrm{a}$ \\
LED-1500 & \\
Root-reinforcement region & Mean $\pm \mathrm{SD}$ \\
Cervical & $4.94 \pm 2.02 \mathrm{a}$ \\
Middle & $2.77 \pm 1.08 \mathrm{~b}$ \\
Apical & $1.92 \pm 0.87 \mathrm{c}$ \\
\hline
\end{tabular}

Different letters indicate statistically significant difference within each independent variable $(p<0.05)$. 
coloration. Resin tags were noted in the dentinal tubules, regardless of the sealer. Group filled with $\mathrm{AH}$ Plus revealed higher penetration of resin material while MTA Fillapex provided less tags. Endofill group exhibited intermediate penetration of adhesive material.

\section{Discussion}

The results of this study evidenced that bond strength of resin material to root dentin was affected by the root canal sealer. AH Plus filling material provided greater bond
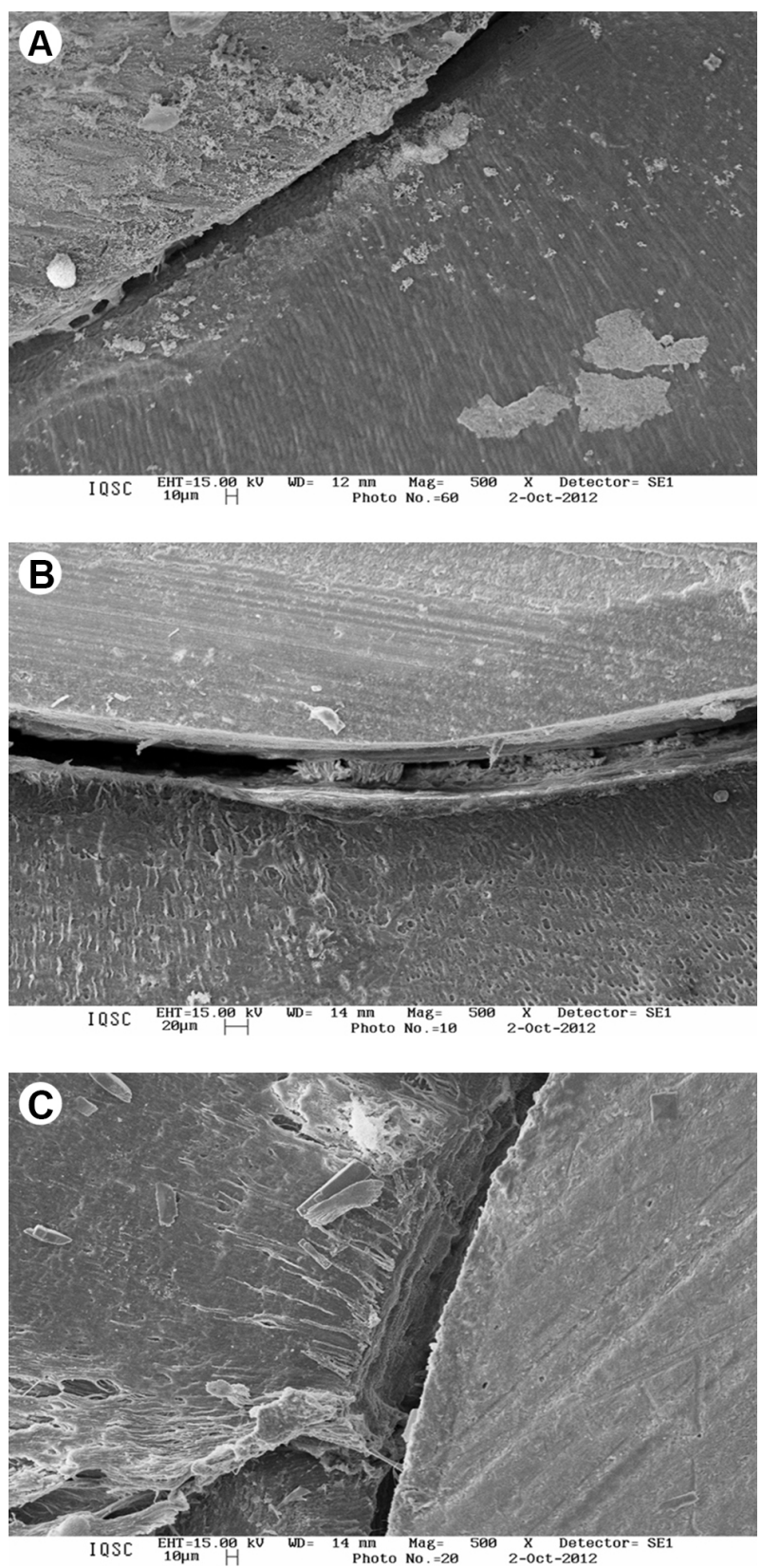

Figure 1. Representative photomicrographs of experimental groups. A: Endofill: presence of gaps between dentin and resin material, B: AH Plus: note the porous and irregular material between dentin and resin, suggestive of root canal sealer, C: MTA Fillapex: note gaps and absence of tags. strength than MTA Fillapex, which was superior to Endofill. Phenolic compounds of eugenol present in Endofill release free radicals that hamper the polymerization of resin-based materials (4). The interaction of resin composite containing Bis-GMA or other dimetracilate compounds with phenolic radicals delays the start of polymerization reaction or accelerates the reaction finishing (15). Additionally, eugenol-containing sealers leave behind an oily layer of debris, which are difficult to remove (16). These aspects
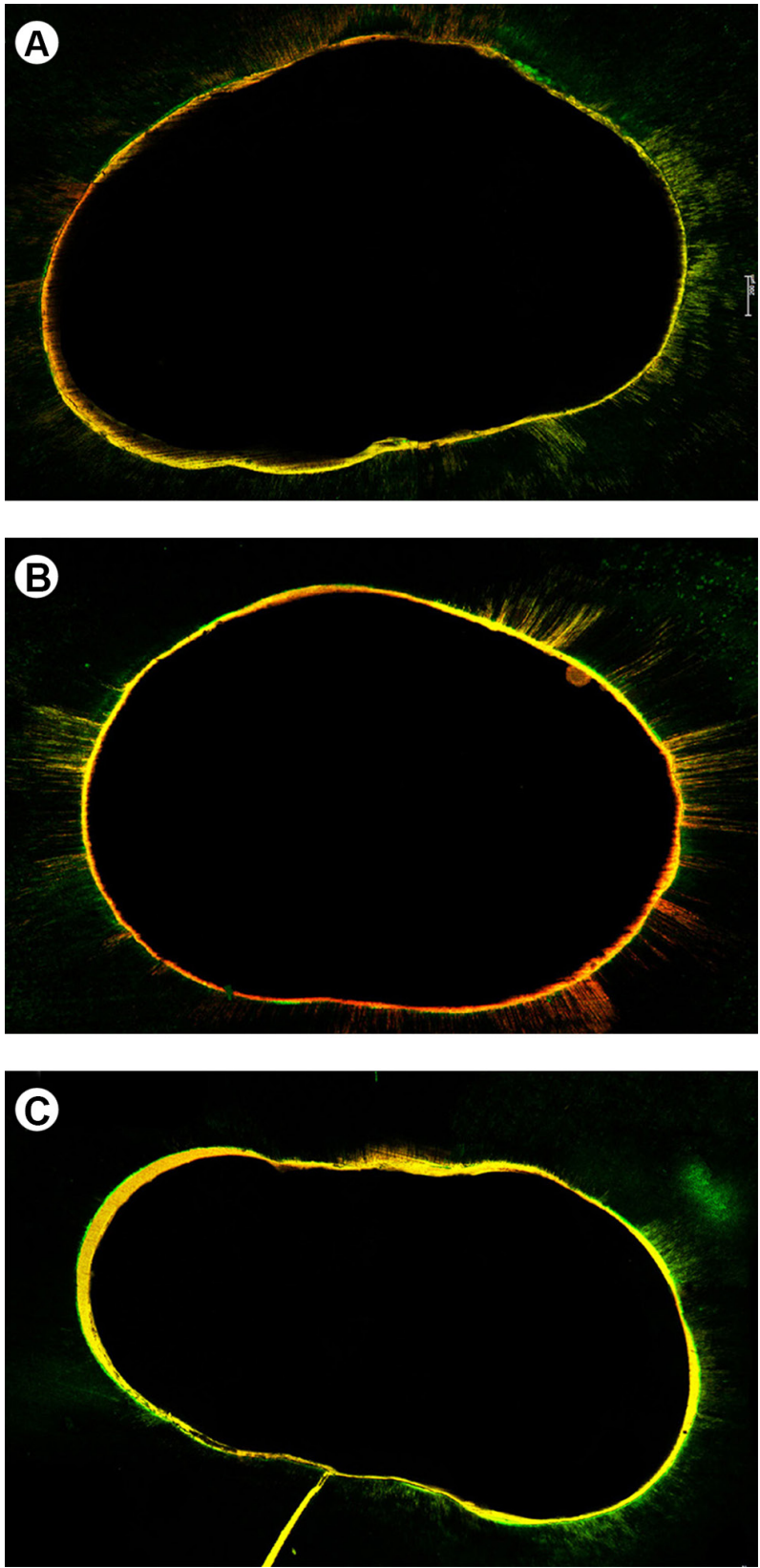

Figure 2. A: Endofill: presence of sealer in dentin walls and tubules (green) and few tags of adhesive (red), B: AH Plus: note residues of filling material in dentinal tubules (green) and intense formation of resin tags (red), C: MTA Fillapex: note remnants of root canal sealer mixed with adhesive in dentin surface (yellow), and low penetration of adhesive in dentinal tubules (red). 
could be reduced the polymerization reaction and provided poor adhesive penetration in root dentin, affecting dentin bonding as verified in this investigation.

MTA Fillapex had lower bond strength than AH Plus, similar to results found by Teixeira et al. (2) Calcium and hydroxil ions released by MTA during setting reaction lead to formation of residual apatite (17), which is deposited between the dentin collagen fibrils forming tag-like structures alongside the interfacial layer. However, these microstructures have low bond strength to the dentin (18). Confocal microscopy images evidenced that the remaining MTA Fillapex into dentinal tubules impaired the adhesive penetration. Probably, the low bond capacity of resin composite to root for MTA Fillapex group and the lack of penetration in the dentinal tubules can explain the reduced bond strength observed in this study.

AH Plus sealer presents favorable physicochemical properties (10) and adhesion to root canal walls (19). In addition, the affinity between epoxy-resin based sealers and resin materials (4) can improve the bond strength to root dentin. The confocal microscopy analysis showed residues of sealer and tags formation. These characteristics and the possible chemical interaction can justify the cohesive failures observed in the group filled with AH Plus.

In this study, LED curing units used to light-activate resin material had higher power density and mechanisms of heat control (20). The present outcomes evidenced greater bond strength after light-curing with LED-1500, followed by LED-800 and OTH-600. A possible explanation is that the light emitted by the LEDs is concentrated in a spectral region that better interacts with camphorquinone, which is the major photo-initiator in most resin materials while the greater attenuation and scattering of halogen curing light may compromise the interaction of light with the photoinitiator $(11,12$,$) . Considering that optimum efficiency$ photoinitiator activation occurs at specific wavelengths and that is obtained if the peak absorptivity of the photoinitiator corresponds to the spectral emission (21), the composite resin polymerization activated by high power LED can be improved (12). In addition, LED-1500 has an association with one or more low power density chips that emit light wavelengths able to activate different photo-initiators providing increased bond strength of resin materials to dentin surfaces (11).

Light-curing units with relatively low irradiances may provide insufficiently cured composites (12) and compromised bond strength to dentin. In OTH lamps, part of energy is used to convert monomers into polymers and the remaining is lost as heat (19). Additionally, low-powered LED units require higher exposition time to achieve similar performance to that of high-power LED (11). The energy density for each group was standardized since we used the same light curing unit (allocated for each group) and the light output of each curing unit was checked with radiometer before each reinforcement procedure to ensure accurate light intensity. Furthermore, the time of light application was the same for each group.

In this study, bond strength in the cervical rootreinforcement region was higher than in middle and apical parts. This finding corroborates with previous investigations (6). Excess of adhesive has been described in the apical region due to the solvent evaporation that could impair the adhesive penetration into the dentinal tubules (22), compromising the bond strength. In addition, portions of adhesive less polymerized and presence of bubbles have been found in the apical region (16). The differences among root-reinforcement region can also be explained by anatomic and histologic characteristics of root dentin, with fewer dentin tubules (23) and less divergent (24) toward the apical portion. Furthermore, the reduced range of light toward the root canal (8) can jeopardize the polymerization of resin material, impairing the bond strength to the dentin.

The superior bond strength found in the cervical root-reinforcement region of specimens filled with $\mathrm{AH}$ Plus, and light-cured with LEDs are in accordance with the predominant failure pattern (cohesive) observed in these groups.

The current results suggest interference of eugenol in the polymerization of resin-based materials, even that high power light-curing units favor the conversion of monomer into polymer. On the other hand, polymerization contraction can be increased with energy density (25) raising the risk of marginal gaps formation (26). To overcome this issue, the soft-start light-curing technique has been proposed, in which a low initial intensity light is applied followed by a high power density for the remaining polymerization period (26). Further research is needed to clarify the impact on bond strength to dentin of soft-start light-curing units and protocols for cleaning the residues of root canal sealer prior the reinforcement of thin-walled roots.

Based on the results of the present in vitro study, it can be concluded that eugenol-based sealer reduced bond strength of composite resin to dentin of weakened roots. Increased bond strength was provided after lightactivation with LED-1500 $\mathrm{mW} / \mathrm{cm}^{2}$ and in the cervical root-reinforcement region.

\section{Resumo}

0 objetivo neste estudo foi avaliar a influência do cimento endodôntico e da fonte de luz fotoativadora na resistência de união (RU) regional da resina composta às raízes fragilizadas. Noventa raizes de incisivos foram experimentalmente fragilizados, submetidos ao preparo biomecânico e obturadas com Endofill, AH Plus ou MTA Fillapex. Os canais foram desobturados e reforçados com pinos de fibra de vidro e resina composta fotoativada com uma das fontes de luz: halógena a $600 \mathrm{~mW} / \mathrm{cm}^{2}(\mathrm{QTH}-$ 
600), diodo emissor de luz a $800 \mathrm{~mW} / \mathrm{cm} 2$ (LED-800) e LED a $1500 \mathrm{~mW} /$ $\mathrm{cm}^{2}$ (LED-1500). As raizes foram seccionadas em slices provenientes dos terços cervical, médio e apical das regiões da raiz reforçada e analisadas por meio do teste de push out, microscopia eletrônica de varredura (MEV) e microscopia confocal de varredura a laser (MCVL). Os dados de resistência de união foram analisados por ANOVA a três critérios e teste de Tukey $(\alpha=0,05)$. Os espécimes obturados com AH Plus apresentaram maior resistência de união, seguido do MTA Fillapex e do Endofill $(p<0,05)$. Para fonte de luz fotoativadora, LED-1500 apresentou resistência de união superior ao LED-800 que foi maior que $0 T H-600(p<0,05)$. A região cervical obteve as maiores médias $(p<0,05)$, enquanto que a região apical apresentou a menor resistência de união $(p<0,05)$. MCVL revelou remanescente de material endodôntico nos túbulos dentinários para todos os grupos. 0 cimento contendo eugenol (Endofill) comprometeu a resistência de união da resina composta à dentina radicular. A resistência de união foi favorecida na região cervical, e quando o LED-1500 foi empregado.

\section{References}

1. Teixeira CS, Silva-Sousa YC, Sousa-Neto MD. Effects of light exposure time on composite resin hardness after root reinforcement using translucent fiber post. J Dent 2008;36:520-528.

2. Teixeira CS, Silva-Sousa YC, Sousa-Neto MD. Bond strength of fiber posts to weakened roots after resin restoration with differents lightcuring times. J Endod 2009;35:1034-1039.

3. AlEisa $\mathrm{K}, \mathrm{Al}$-Dwairi ZN, Lynch $\mathrm{E}$, Lynch $\mathrm{CD}$. In vitro evaluation of the effect of different endodontic sealers in retentive strenght of fiber posts. Oper Dent 2013;38:539-544.

4. Altmann AS, Leitune VC, Collares FM. Influence of eugenol-based sealers on push-out bond strength of fiber post luted with resin cement: Systematic review and meta-analysis. J Endod 2015;41:14181423.

5. Teixeira CS, Felippe MCS, Silva-Sousa YT, Sousa-Neto MD. Interfacial evaluation of experimentally weakened roots restored with adhesive materials and fiber posts: an SEM analysis. J Dent 2008;36:672-682.

6. Miguel-Almeida ME, Azevedo MLC, Rached-Júnior FA, Oliveira CF, Silva RG, Messias DC. Effect of light-activation with different lightcuring units and time intervals on resin cement bond strength to intraradicular dentin. Braz Dent J 2012;23:362-366.

7. Bahari M, Savadi Oskoee S, Kimyai S, Mohammadi N, Saati Khosroshahi E. Effect of light intensity on the degree of conversion of dual-cured resin cement at different depths with the use of translucent fiber posts. J Dent 2014;11:248-255.

8. Yoldas 0, Alaçam T. Microhardness of composites in simulated root canals cured with light transmitting posts and glass-fiber reinforced composite posts. J Endod 2005;31:104-106.

9. Reges RV, Costa AR, Correr AB, Piva E, Puppin-Rontani RM, Sinhoreti $M A$, et al. Effect of light-curing units, post-cured time and shade of resin cement on knoop hardness. Braz Dent J 2009;20:410-413.

10. Marciano MA, Guimarães BM, Ordinola-Zapata $R$, Bramante $C M$, Cavenago BC, Garcia RB, et al. Physical properties and interfacial adaptation of three epoxy resin-based sealers. J Endod 2011;37:14171421.
11. Rueggeberg FA, Blalock JS, Callan RS. LED curing lights - what's new. Compend Contin Educ Dent 2005;26:586- 590.

12. Santos MJ, Passos SP, Encarnação MO, Santos-Junior GC, Bottino MA. Hardening of a dual-cure resin cement using QTH and LED curing units. J Appl Oral Sci 2010;18:110-115.

13. Visvanathan $A$, llie N, Hickel $R$, Kunzelmann KH. The influence of curing times and light curing methods on the polymerization shrinkage stress of a shrinkage-optimized composite with hybrid-type prepolymer fillers. Dent Mater 2007;23:777-784.

14. Machado RP, Chaves CA, Rached-Junior FJ, Souza CJ, Messias DC, SilvaSousa YC. Effect of light sources on the bond strength of resin material to thin-walled roots. Braz Dent J 2014;25:225-231.

15. Cohen BI, Volovich Y, Musikant BL, Deutsch AS. The effects of eugenol and epoxy-resin on the strength of a hybrid composite resin. J Endod 2002;28:79-82.

16. Schwartz RS. Adhesive Dentistry and Endodontics. Part 2: Bonding in the Root Canal System- The Promise and the Problems: A Review. J Endod 2006;32:1125-1134.

17. Sarkar NK, Caicedo R, Ritwink P, Moiseyeva R, Kawashima I. Physicochermical basis of the biologic properties of mineral aggregate. J Endod 2005;31:97-100.

18. Sagsen B, Ustun S, Demirbuga S, Pala K. Push-out bond strength of two new calcium silicate- based endodontic sealers to root canal dentine. Int Endod J 2011;44:1088-1091.

19. Asmussen $E$, Peutzfeldt A. Temperature rise induced by some light emitting diode and quartz-tungteb-halogen curing units. Eur J Oral Sci 2005;113:96-98.

20. Krämer N, Lohbauer U, Garcia-Godoy F, Frankenberger R. Light curing of resin-based composites in the LED era. Am J Dent 2008;21:135-142.

21. Segreto DR, Naufel FS, Brandt WC, Guiraldo RD, Correr-Sobrinho L, Sinhoreti MA. Influence of photoinitiator and light-curing source on bond strength of experimental resin cements to dentin. Braz Dent J 2016;27:83-89.

22. Tay FR, Pashley DH. Aggressiveness of contemporary self-etching systems. I: Depth of penetration beyond dentin smear layers. Dent Mater 2001;17:296-308.

23. Shemesh $H$, Wu MK, Wesselink PR. Leakage along apical root fillings with and without smear layer using two different leakage models: a two-month longitudinal ex vivo study. Int Endod J 2006;39:968-976.

24. Lertchirakarn V, Palamra JEA, Messer HH. Anisotropy of tensile strength of root dentin. J Dent Res 2001;80:453-456.

25. Bouillaguet $\mathrm{S}$, Troesch S, Wataha JC, Krejci I, Meyer JM, Pashley DH. Microtensile bond strength between adhesive cements and root canal dentin. Dent Mater 2003;19:199-205

26. Tauböck T, Feilzer AJ, Buchalla W, Kleverlaan CJ, Krejci I, Attin T. Effect of modulated photo-activation on polymerization shrinkage behavior of dental restorative resin composites. Eur J Oral Sci 2014;122:293-302.

Accepted April 29, 2016

Received August 12, 2016 